American Journal of Applied Sciences 8 (10): 1045-1053, 2011

ISSN 1546-9239

(C) 2011 Science Publications

\title{
Electromagnetic Interference Mitigation for Inverter fed AC Drives
}

\author{
${ }^{1}$ C. Karthikeyan and ${ }^{2}$ K. Duraiswamy \\ ${ }^{1}$ Departmetnt of EEE, \\ ${ }^{2}$ Departmetnt of CSE, \\ K.S.R. College of Technology, \\ Tiruchengode-637215, (TN), India
}

\begin{abstract}
Problem statement: In switched mode PWM inverter EMI noise occurs during high (dv/dt) transient period. This EMI noise is mitigated using Active Common mode EMI filter in front of the source. Approach: This study proposes a new active common mode Electromagnetic Interference (EMI) filter for switched mode PWM Inverter applications. The proposed filter is based on current sensing and compensation circuit which utilizes fast transistor amplifier for current compensation. The amplifier is biased with an isolated low voltage DC power supply. Hence it is possible to construct an active filter independent of the source voltage of equipment. Thus this filter can be used in any application regardless of working voltage. The proposed switched mode PWM inverter operated in $180^{\circ}$ mode of operation. It's otherwise called as quasi square wave mode. Results: Simulation of output wave form is verified by using MATLAB Simulink model results and also its effectiveness has been verified hardware output wave forms. The hardware for this project is designed and developed for $50 \mathrm{~V}, 50 \mathrm{~Hz}$ three phase Fractional Horse Power (FHP) motor. Conclusion: In this Study the concept of the new active common mode EMI filter and quasi square PWM inverter has been proposed. The corresponding simulated output waveforms are verified with the Active Common mode EMI filter; it is possible to use low-voltage transistors for the amplifier by introducing coupling capacitors between the power line and the amplifier circuit. Thus the ACEF can be applied to various power electronic systems regardless of the working voltage. Also it helps in improving the performance of additional filter stages.
\end{abstract}

Key words: Active Common mode Electromagnetic Interference Filter (ACEF), Switched mode (QS wave mode), PWM Inverter, EMI noise, Fractional Horse Power (FHP), DC power, Electromagnetic Interference (EMI), wave forms

\section{INTRODUCTION}

Switched-mode DC to AC Inverters are used in $\mathrm{AC}$ motor drives and uninterruptible $\mathrm{AC}$ power supply where the objective is to produce AC output whose magnitude and frequency can both be controlled. Since the input give to switched-mode or quasi square PWM inverter is fixed DC voltage source, such inverters are referred to as Voltage Source Inverter (VSI). So VSI is used in very high power AC motor drives (Mohan et al., 2003). It is classified into three categories (a) PWM Inverter (b) Square Wave PWM Inverter and (c) Single Phase Inverter with voltage cancellation. The PWM Inverter is inherent noise source that makes abrupt voltage transitions (high $\mathrm{dv} / \mathrm{dt}$ ) companied by switching actions (Skibinski et al., 1999; Karthikeyan and Duraiswamy, 2011). It is coupled with the stray capacitance of the load machine the high frequency current is generated, which affects the operation of nearby equipment due to the conducted and radiated EMI. An increase in $(\mathrm{dv} / \mathrm{dt})$ increases the EMI level. The EMI is transmitted in two forms (1).Radiated noise (2).Conducted noise. This EMI noise is filtered by using filter (Mohan et al., 2003; Tihanyi, 1995; Nave, 1991). In conventional passive filter, both inductance and capacitance vary, so system will not be stable in condition. Proposed filter is a New Active Common mode Electromagnetic Interference Filter (ACEF). In this filter Inductance (L) only is varied while capacitance is kept constant. So the system will be stable (Tihanyi, 1995) andActive Common Mode EMI filters regardless of working voltage of system. Its analysis and simulation results are verified.

Corresponding Author: C. Karthikeyan, Department of EEE, K.S.R. College of Engineering, Tiruchengode-637215, (TN), India 
Am. J. Applied Sci., 8 (10): 1045-1053, 2011

\section{MATERIALS AND METHODS}

Switched Mode PWM inverter noise: Rapid change in voltage and current of a switching power converter EMI is in two forms: Radiated and conducted. The radiated EMI is emitted through free space to other equipments, while conducted EMI is transmitted via the circuit connection (Karthikeyan and Duraiswamy, 2011). The radiated EMI can usually be shielded by metal cabinets used for housing the power converter and conducted EMI is reduced by using filter to block its transmitting paths. However, because both the conducted EMIs come from the same energy source and energy is dissipated somewhere, blocking the conducted EMI can often lead to increase in radiation. (Rao et al., 2011) Therefore an effective EMI suppression strategy has to be made on a thorough understanding of the EMI mechanism, so that EMI will be reduced at the source instead only being blocked after it is generated. Since the radiated EMI paths are difficult to define, a complete analysis of the EMI mechanism based on radiation seems practical. On the other hand, the conducted EMI should be helpful in locating the EMI source and understanding the mechanism of EMI generation. A solution aimed at reducing EMI generation at its source, will then become possible for reducing simultaneously and effectively both the radiated and conducted EMIs. It is therefore the focus of this study to analyze the mechanism of EMI generation in AC motor drives based on conducted paths. The conducted EMI can be generated by either coupling currents or inductive load current switching.

EMI caused by capacitive coupling current: A coupling current is the sum of current in parasitic capacitors when they are excited by the high $\mathrm{dv} / \mathrm{dt}$ and high amplitude square wave voltages. Although the coupling current does not affect the basic drive functionality, it does produce certain unwanted second order effects, such as the bearing current shaft voltages (Karthikeyan and Duraiswamy, 2011). A coupling current is composed of two components: A Differential mode and a Common mode.

Differential mode EMI is caused by differential mode coupling current: The differential mode coupling current comes from the following parasitic capacitors between inverter phases, such as $C_{d}$ which represents the phase to phase parasitic capacitance of the motor windings. A high frequency current is produced when the square wave line to line voltage energizes those parasitic capacitors. Just like the inverter load current, the current has to source from the DC link. Assuming a stiff DC link, most of the differential mode coupling current will circulate locally in the loop formed by the DC link capacitor, inverter poles and motor as indicated by the bold dashed line Fig. 1.

Common mode EMI is caused by differential mode coupling current: The Common mode coupling current flows in parasitic capacitors between drive components and earth ground, such as $\mathrm{Cc}$ which represents capacitance between the motor windings and grounded enclosure. Unlike differential mode current, the common mode currents will not return via the local path from the negative rail of the inverter poles to the negative DC bus. Instead all of them flow into the ground and have to return via the ground to the source. Assuming relatively high impedance between negative DC bus and the ground, the main path for common mode coupling currents in an inverter drive with a rectifier input can be depicted as shown in Fig. 2.

EMI Caused by Inductive Load Current Switching: The load current and PWM switching frequency are known to be major contributors to the EMI spectrum. In fact, the load current switching mechanism can lead to EMI produced in both PWM switching frequency and load phase commutation frequency. Particularly, in each PWM switching cycle, load current is transferred from one switch to diode in inverter; Current drawn from the DC link must change abruptly. This process produces a pulsating DC link current in the PWM frequency with its amplitude proportional to the load current. This pulsating current will find its way into AC battery source and become a source of EMI.

\section{Suppuration of Conducted EMI Noise: \\ Suppression of common mode caused by coupling current: The common mode coupling current is a major EMI current component (Chen, 1999) Several approaches are proposed which are summarized following.}

Local circulation of coupling current: This approach provides a path for common mode current to circulate locally between the inverter and the motor only and thus preventing their flow into the battery and to the ground as shown in Fig. 3. 


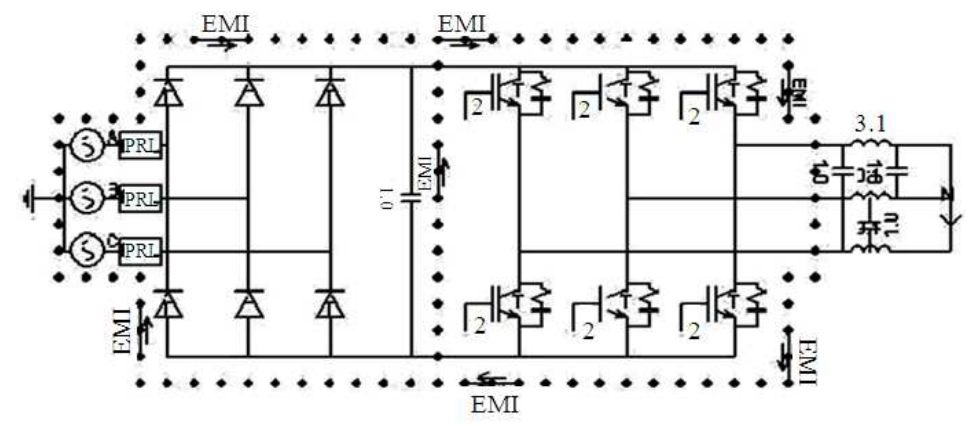

Fig. 1: Differential mode coupling current contributed to conducted EMI

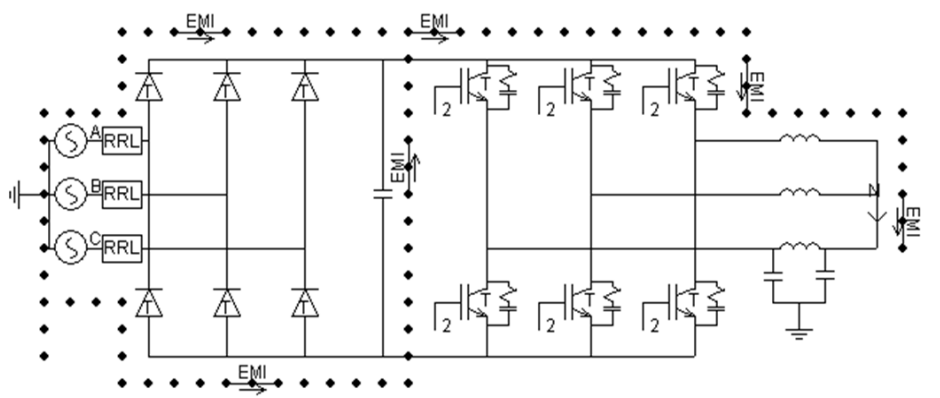

Fig. 2: Common mode coupling current contributed to conducted EMI

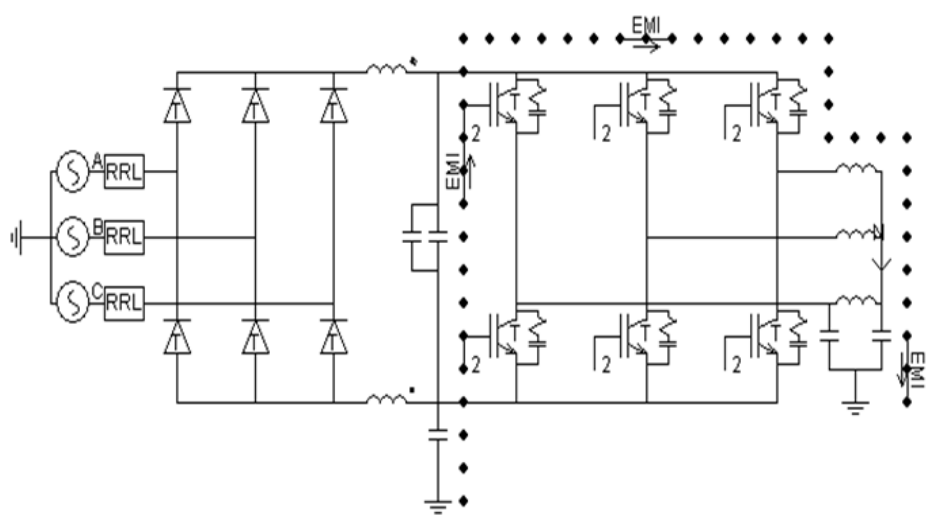

Fig. 3: Circulation of common mode coupling current for reducing common mode EMI

A small capacitor $\mathrm{C}_{\mathrm{n}}$ connected from the negative DC bus to the ground will provide such a circulating path for the common mode current assuming that the DC link has a high frequency capacitor $\mathrm{C}_{\mathrm{f}}$ to provide the common mode currents. A common mode choke $\mathrm{L}_{\mathrm{c}}$ inserted in the DC bus may be added to further enhance the effectiveness of this method. In order to maximize local circulation and minimize emission to the ground plane, it is suggested that the capacitor must be close to where the motor is grounded.
Common mode voltage cancellation: Another innovative solution to the common mode EMI is to use the so-called common mode voltage cancellation technique. This method is to cancel the common mode voltage at the source and thus eliminate all common mode currents. The concept of the common mode cancellation first appeared in and was applied with certain success to motor bearing current reduction. As bearing currents are essentially a type of common mode current, the same techniques should apply to the common mode EMI. 
Analysis of active common mode EMI filter: Figure 4 shows the basic concept of the proposed active common-mode EMI filter (ACEF).This circuit is based on the topology using the current sensing and compensation (Poon et al., 2000; Son and Sul, 2001; Takahashi et al., 1997). The noise source is the PWM inverter in Fig. 5 and the input filter can be an additional passive filter, which gives additional insertion loss. The series-connected common-mode choke works as common-mode $\mathrm{L}_{\mathrm{CM}}$ current sensing element by the additional winding. The high frequency current that passes through $\mathrm{L}_{\mathrm{CM}}$ generates high frequency flux in the common-mode choke, which makes high frequency voltage at the input terminal of trans-conductance amplifier. The output of the amplifier is connected to the output capacitor $\mathrm{C}_{\mathrm{O}}$ so that it is used for the current injection to the earth ground. In this filter circuit, injected current cannot be circulated within the system without using the coupling capacitor $\mathrm{C}_{\mathrm{C}}$ because a closed loop cannot be made. Thus is used to provide low-impedance path of high frequency common-mode current for the internal circulation. The supply voltage of the filter circuit is used to give the bias voltage to the amplifier. At low frequency, impedance $C_{C}$ is large enough to isolate the bias voltage from the main voltage. The required bias voltage of ACEF can be calculated as in Eq. 1. For example, if $0.5 \mathrm{~A}$ of high frequency current at $1 \mathrm{MHz}$ should be supplied, then the bias voltage should be larger than $7.96 \mathrm{~V}$ in order to drive a $10 \mathrm{nF}$ capacitor $\mathrm{C}^{\prime}{ }_{\mathrm{O}}$, which is the series impedance of the output capacitor $\mathrm{C}_{\mathrm{O}}$ and the coupling Capacitor $\mathrm{C}_{\mathrm{C}}$ Fig. 6 shows the application of the proposed ACEF:

$\mathrm{V}_{\mathrm{c}} \geq \max \mathrm{i}_{\mathrm{o}} / 2 \pi \mathrm{fc}$ 。

In this example a single-phase, three phase andDC applications are shown. As introduced in (Nave, 1991), a push-pull amplifier is used and is connected to the DC-bus of the PWM inverter or any DC load system. In case of PWM inverter supplied by the commercial 50 $\mathrm{Hz} / 220 \mathrm{~V}$ utility lines, the DC-bus voltage is about 300 $\mathrm{V}_{\mathrm{dc}}$. If the push-pull amplifier should be placed across the DC-bus capacitor as suggested in (8), then each transistor should be able to handle the full DC-bus voltage. The high-voltage/high-current pnp-transistor is hardly available; hence that limits its application. Moreover the required voltage of the push-pull amplifier is very small compared to the DC-bus voltage as shown in Eq. 3 and it can make inefficient the voltage usage. However in the proposed circuit the additional low voltage supply can be used to drive the push-pull amplifier. This enables the use of low voltage devices and extends the application of the proposed ACEF. Figure 6a shows its application, when coupling capacitors are placed in between the DC-bus voltage and the filter supply voltage. While coupling capacitors in Fig. 6a, isolate the DC-bus and the ACEF at low frequency, they make low impedance path at high frequency, which allows the internal circulation of high frequency leakage current between the system and the ACEF as introduced in (7). The filter supply voltage can be easily obtained by using a DC power supply fed to the control electronics such as a gate drive circuit. Unlike an ideal voltage source, there can be some voltage ripple in the filter supply, if a Switched Mode Power Supply (SMPS) is used for this DC power supply. In this case, the noise produced by the DC power supply may flow into the DC bus through the coupling capacitors $\mathrm{C}_{\mathrm{C}}$ in Fig. 6a, which may affect the total conducted EMI including the PWM inverter and the proposed ACEF. Besides the high- frequency noise produced by the PWM inverter, can be transmitted to the control electronics via the coupling capacitors CC with the same manner. Thus the filter supply should provide sufficient low impedance, to decouple such high-frequency noises. Coupling capacitors also can be connected to ac input lines of the system as shown in Fig. $6 \mathrm{~b}$ and it is possible to construct a separate input filter stage.

The same idea can be extended to the three phase applications, which is shown in Fig. 6c and d. The proposed circuit works as follows. In this analysis there is an assumption that coupling capacitors have sufficient low impedance at the frequency band of interest. If the inductance of the common-mode choke seen at the primary winding is without the consideration of secondary winding, then the relation between input common-mode current and base current of the pushpull amplifier can be found as Eq. 2:

$\mathrm{i}_{\mathrm{b}} / \mathrm{i}_{\mathrm{g}}=-\mathrm{N} . \mathrm{s} / \mathrm{s}+\omega_{1}$ and $\omega_{1}=\mathrm{N}^{2} \mathrm{r}_{\mathrm{i}} \mathrm{n} / \mathrm{L}_{\mathrm{CM}}$

where, $\mathrm{N}$ is the turn's ratio between the primary winding and the secondary winding, rin is the input impedance of the push-pull transistor amplifier including the additional resistor. If the leakage inductance of common-mode choke can be negligible, the common-mode inductance $\mathrm{L}_{\mathrm{CM}}$ can be represented as Eq. 3:

$$
\mathrm{L}_{\mathrm{CM}}=\mathrm{N}^{2} \mu \mathrm{Ae} / \ell_{\mathrm{e}}
$$




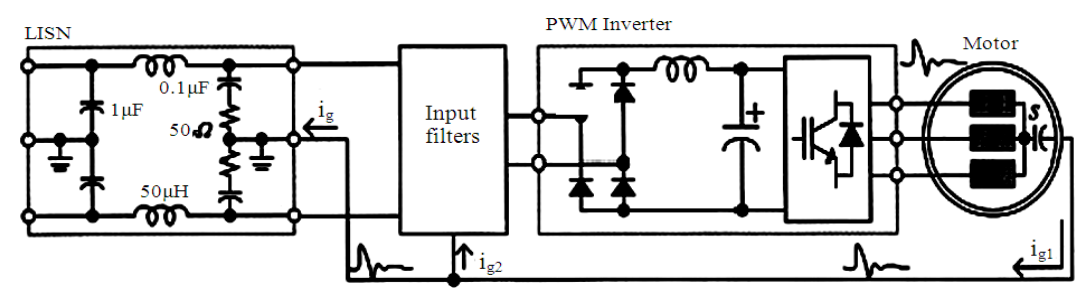

Fig. 4: PWM inverter systems for three phase motor

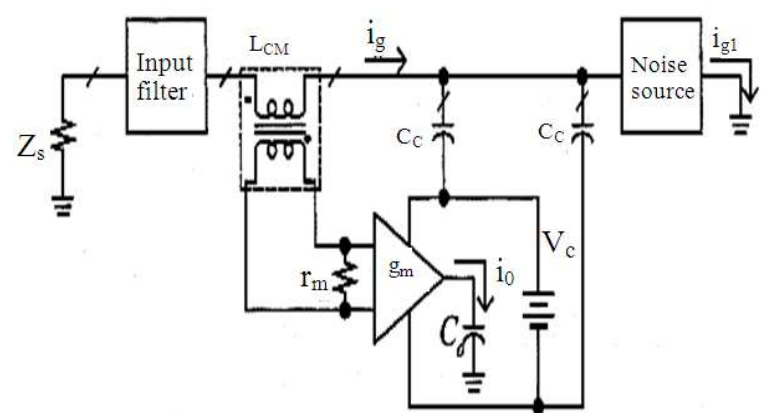

Fig. 5: Basic concept of proposed ACEF

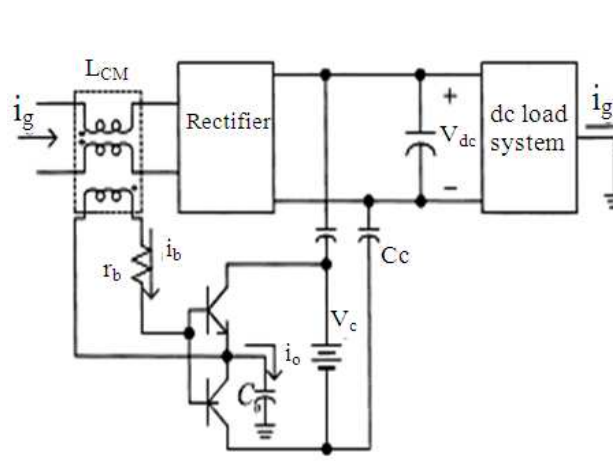

(a)

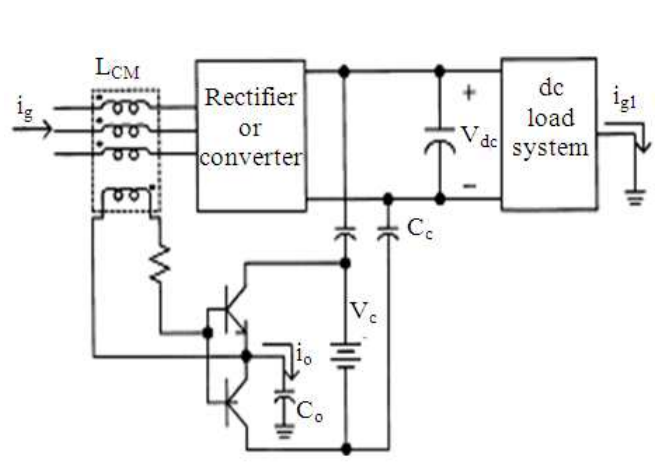

(c)

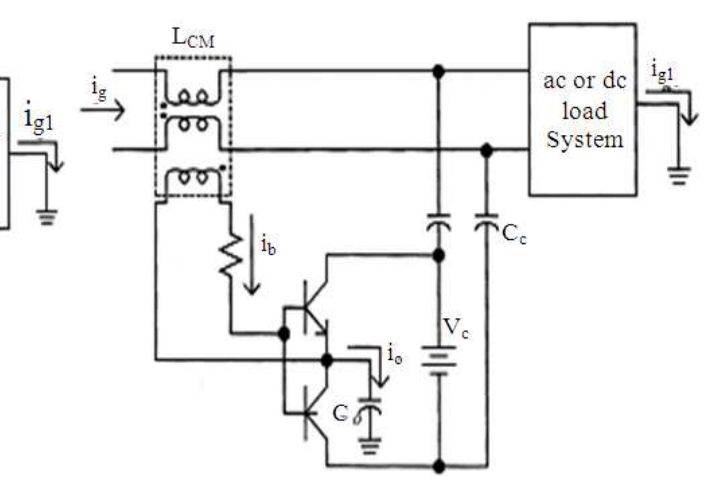

(b)

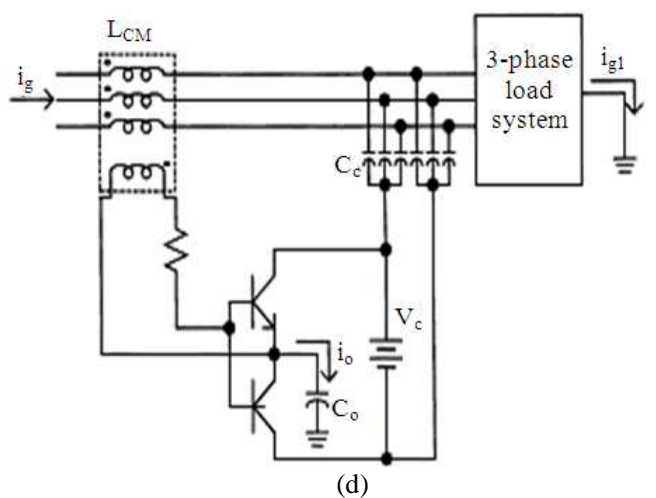

(d)

Fig. 6: Configurations of proposed ACEF: (a) ACEF using DC -bus coupling, (b) ACEF using AC line coupling for single-phase application, (c) ACEF using DC-bus coupling (d) ACEF using AC line coupling for three-phase application 


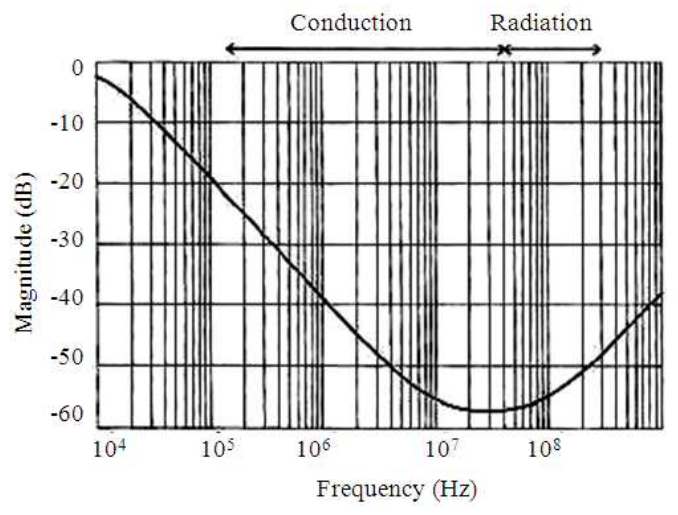

Fig. 7: Frequency response of proposed ACEF

where, $\mu$ is the relative permeability, $A_{e}$ is the effective area and $\ell_{\mathrm{e}}$ is the effective length of the magnetic core. Thus the cutoff frequency can be represented as Eq. 4 regardless of the number of turns:

$\omega_{1=} \mathrm{r}_{\mathrm{in}} \ell \mathrm{e} / \mu \mathrm{A}_{\mathrm{e}}$

If the bandwidth of the transistor amplifier is a first-order system, then the injection current of the amplifier can be derived as Eq. 5:

$\mathrm{i}_{\mathrm{o}}=\mathrm{h}_{\mathrm{fe}} /\left(1+\mathrm{s} / \omega_{\mathrm{r}}\right) \cdot \mathrm{i}_{\mathrm{b}}=\mathrm{Nh}_{\mathrm{fe}} /\left(1+\mathrm{s} / \omega_{\mathrm{r}}\right) \cdot\left(\mathrm{s} / \mathrm{s}+\omega_{1}\right) \cdot \mathrm{i}_{\mathrm{s}}$

where, $\mathrm{h}_{\mathrm{fe}}$ is the ac current gain of the transistor. Because the input common-mode current is the sum of injection current $i_{o}$ and the load leakage current $i_{g 1}$, then the relation between $i_{g}$ and $i_{o}$ can be found as $E q$ 6:

$$
\mathrm{i}_{\mathrm{g}=\mathrm{i}} \mathrm{i}_{\mathrm{o}}+\mathrm{i}_{\mathrm{g} 1}=\frac{\left(1+\mathrm{s} / \omega_{\mathrm{r}}\right) \mathrm{X}\left(\mathrm{s} / \mathrm{s}+\omega_{1}\right)}{\left[1+\left(1 / \omega_{\mathrm{T}}+1+\mathrm{Nh}_{\mathrm{fe}}\right) \mathrm{s}+\mathrm{s}^{2} / \omega_{\mathrm{T}} \omega_{1}\right]}
$$

If the bandwidth of the transistor amplifier is high, then Eq. 6 can be simplified as Eq. 7:

$$
\operatorname{ig} \approx \frac{\left(1+\mathrm{s} / \omega_{\mathrm{r}}\right) \cdot\left(\mathrm{s} / \mathrm{s}+\omega_{1}\right)}{\left(1+\mathrm{s} / \omega_{2}\right) \cdot\left(\mathrm{s} / \mathrm{s}+\omega_{3}\right)}
$$
Eq. 8:

If $\omega_{\mathrm{T}}$ is much higher then, Eq. 7 is approximated as

$$
\mathrm{ig} \approx \frac{\left(1+\mathrm{s} / \omega_{\mathrm{r}}\right)}{\left(\mathrm{s} / \mathrm{s}+\omega_{2}\right)} * \mathrm{ig}_{1}
$$

Figure 7 shows the frequency response of the proposed ACEF without including the effect of coupling capacitors. As it can be seen from the figure, the approximation holds in the conducted EMI frequency band, 0.15-30 MHz. But the attenuation performance is degraded in the radiated EMI frequency band, 30-300 MHz, due to the limited bandwidth of the transistor amplifier. The maximum attenuation of $1 /(1+$ Nhfe $)$ is achieved between $\omega_{1}$ and $\omega_{\mathrm{r}}$. Simple passive filters can be inserted at the input or output of the transistor amplifier to reduce the effect of limited performance in the radiated EMI frequency band. Also as for the inflow of low-frequency leakage current, it cannot be attenuated because of the nature of coupling capacitors and the sensing circuit. The equivalent inductance of the common-mode choke, due to the $\mathrm{ACEF}$ can be calculated using the relation shown in Eq. 2 and it is given as Eq. 9 combined with Eq. 7-9 the input common-mode current, can be effectively suppressed without increasing the low frequency leakage current:

$$
\mathrm{L}_{\mathrm{CM}}=\mathrm{L}_{\mathrm{CM}} *(1 /(1+\mathrm{s}) / \omega 1)
$$

\section{RESULTS}

The simulating circuit consists of input active filter and the PWM inverter. Input filter consists of the combination ACEF and transistor amplifier. Input filter transistor amplifier Q1 and Q2 base biased by three winding mutual in inductance Single phase $200 \mathrm{~V}$ AC supply is given to the input filter. The EMI noise filter output is given to the rectifier input. A pure DC voltage is given to the PWM Inverter. In between (Nave, 1989; Jin and Weiming, 2006; Williams, 2009; Nave, 1991; Ogasawara and Akagi, 2000; Lubis et al., 2009) LC used to maintain the constant current and voltage. Load side stray capacitance is grounded as shown in Fig. 8.

Simulated model for PWM inverter without filter: Let the supply voltage is $200 \mathrm{~V}$ given to the MOSFET Inverter circuit. Switched mode PWM Inverter is operating at $180^{\circ}$ mode. RL Load is connected across the Inverter. Line to Ground voltage is measured using three individual voltmeters. The output wave form of each phase voltage shown in scope. Switching sequence is $612,123,234,345,456$.

The PWM pulses are generated by pulse generator and these pulses are given to the MOSFETs. The Fig. 9 shows the PWM pulse for MOSFETs. Switch S1 is fired at $\omega \mathrm{t}=0^{\circ}$, then $\mathrm{S} 3$ must be fired at $\omega \mathrm{t}=120^{\circ}$ and $\mathrm{S} 5$ at $\omega \mathrm{t}=240^{\circ}$. Same is true for lower group of SCRs. 


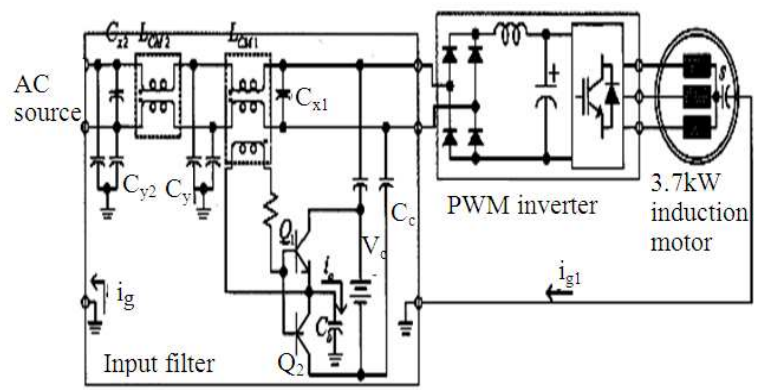

Fig. 8: ACEF with PWM Inverter simulation circuit

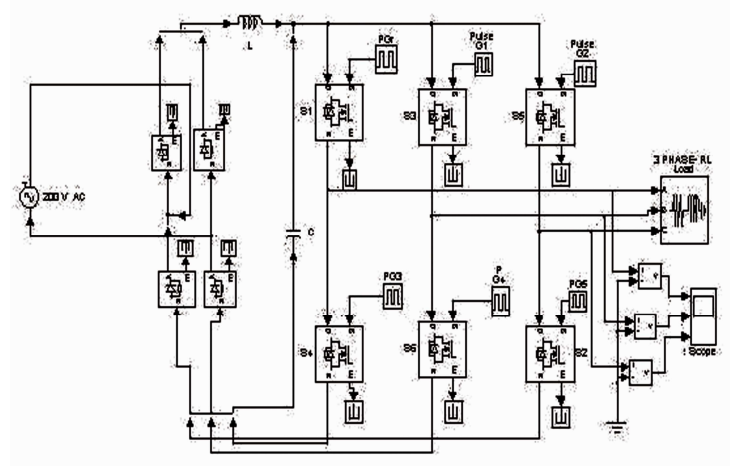

Fig. 9: Simulink model of PWM Inverter without filter

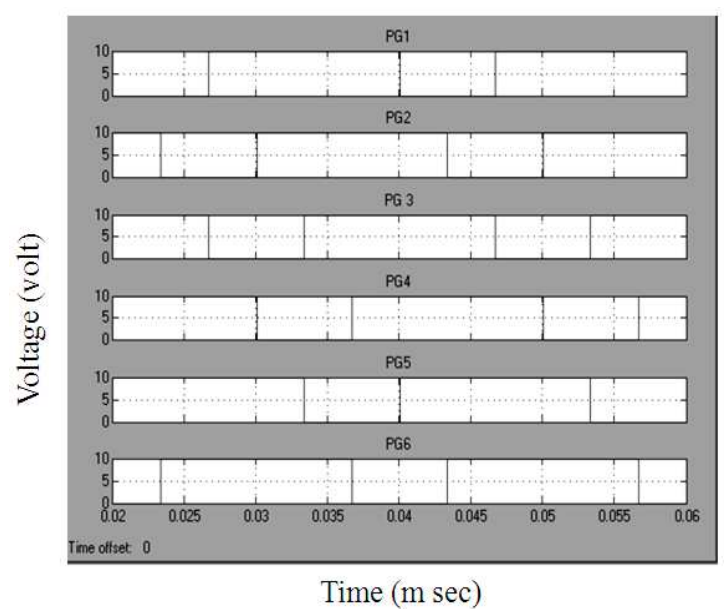

Fig. 10: Pulses for PWM inverter

Simulated output voltage wave form of PWM inverter: Figure 11 shows the simulated output voltage wave form of PWM Inverter. Since there is no filter spikes are produced during the high $\mathrm{dv} / \mathrm{dt}$ transient voltage as shown in figure. This spikes will affect the circulating the common mode current. Due this reason nearby components will be damage.

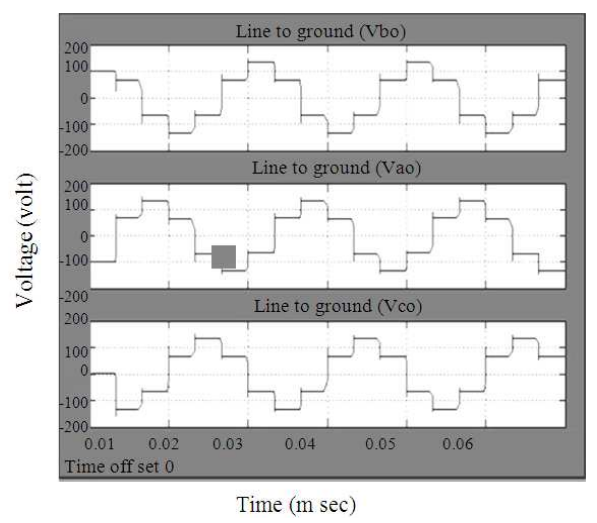

Fig. 11: Output voltage wave form of PWM inverter

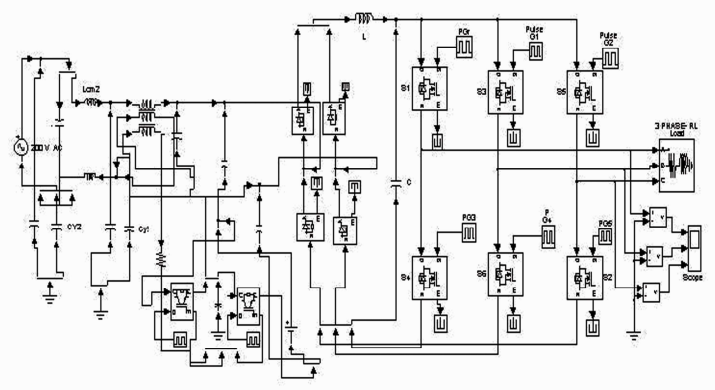

Fig. 12: Simulink model of PWM Inverter with Filter

Simulated quasi square PWM inverter with filter: Figure 12 shows that simulated switched mode PWM Inverter. Input voltage is $200 \mathrm{~V}$ AC supply is given to the input filter. In input filter Inductance is alone varied while keeping the capacitance constant. The Input filter Output is given to the input of the rectifier. The rectifier pure DC voltage is given to the PWM Inverter. In between rectifier and Inverter inductance is used to maintain the constant current. Capacitance is connected across the supply voltage; it is used to maintain the constant voltage.

Simulated output voltage wave form of PWM inverter: In switched mode PWM inverter Active common mode EMI filter used to reduce the EMI noise as shown in Fig. 13. By varying the inductance value the high transient voltage is reduced.

Hardware description and results: Figure 14 shows the block diagram of A New ACEF for switched mode PWM Inverter with 3 phase FHP motor. Input voltage is single phase $110 \mathrm{~V}, 50 \mathrm{~Hz}$ AC supply. Switched mode PWM pulses are generated by 8051 Microcontroller. This pulses amplitude is $+5 \mathrm{~V}$ it will be drive to $+12 \mathrm{~V}$ using Driver circuit. Drive circuit consist of opto 
coupler, PNP and NPN darling done pairs. Output of the driver circuit $+12 \mathrm{~V}$ pulses is given to the switched PWM Inverter IGBTs gate.

Switched mode PWM inverter module: Figure 15. Shows the switched mode PWM Inverter module. EMI noise filter output is given to the rectifier. Rectifier output is given to the input of the Switched mode PWM Inverter and output of switched mode PWM Inverter connected to load (Jin and Weiming, 2006; Ogasawara and Akagi, 2000).

$\mathbf{1 8 0}^{\circ}$ mode PWM pulse delay sequence: Figure 16. Shows the Switched mode PWM Inverter IGBT gate pulse wave form. The switching sequences are 612, 123, 234, 456 and 561. The above figure shows the 561 switching sequence. IGBT 1 and IGBT 5 are upper part of switch turn on. Lower part of IGBT 6 turn on.

Resistive Load Output Wave for Switched mode PWM Inverter: Figure 17 shows the Inverter output voltage for RL load without EMI filter. The waveform contains spikes while turning ON and OFF of the Inverter switch.

Figure 18 shows the Inverter output voltage for RL load with EMI filter. The spikes which are produced by turning $\mathrm{ON}$ and $\mathrm{OFF}$ the Inverter switch is eliminated using EMI filter.

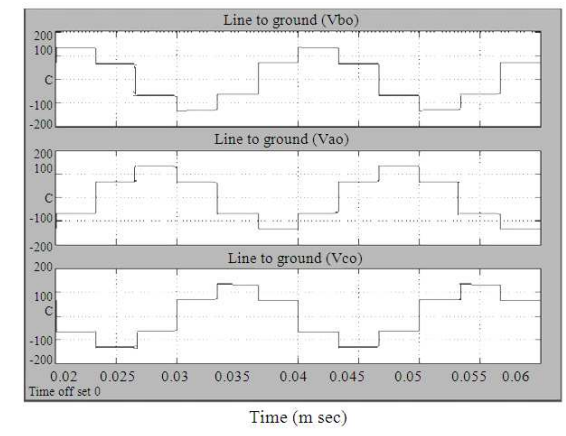

Fig.13: Switched Mode PWM Inverter with Filter output wave form

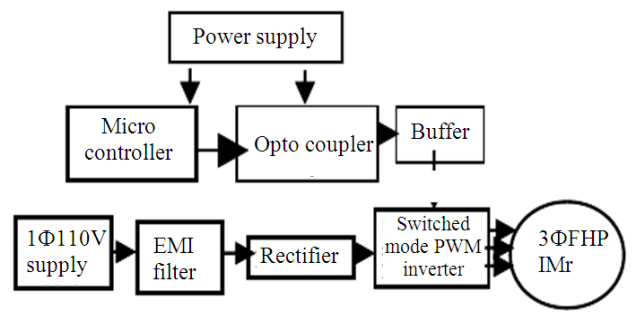

Fig. 14: Block diagram

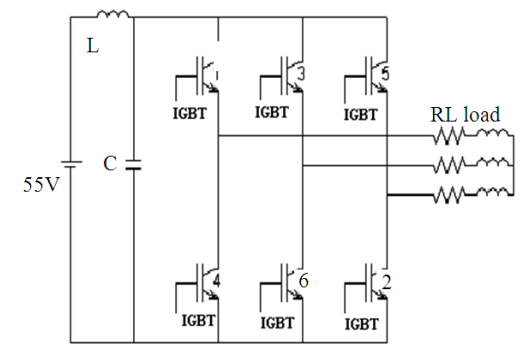

Fig. 15: Switched Mode PWM inverter modules

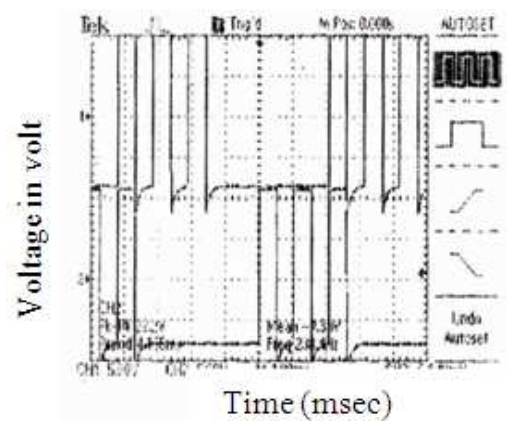

Fig. 16: Gate delay pulse wave form

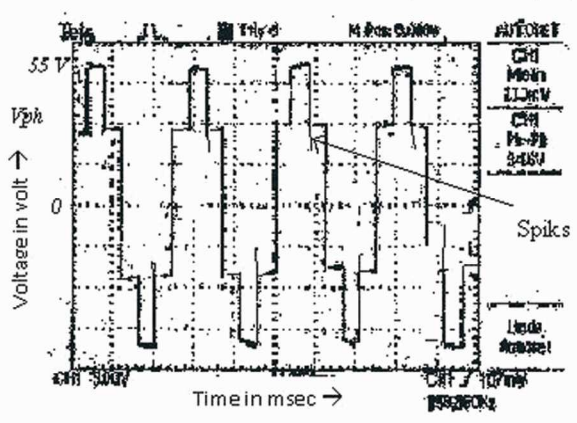

Fig. 17: Without filter output waveform for load

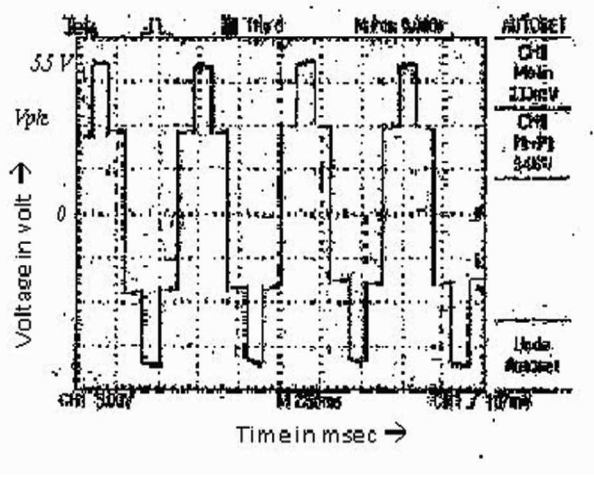

Fig. 18: With filte output waveform for load 1052 


\section{DISCUSSION}

The simulation output wave form Fig. 12 and 17 observed simillar behaver of implimentation output wave form. The obove same figures spiks will interrupt current. These spikes will mitigated by EMI filter introduced in input sized. This output wave form shown in Fig. 13 and 18.

\section{CONCLUSION}

In this Study the concept of the new active common mode EMI filter and quasi square PWM inverter has been proposed. The corresponding simulated output waveforms are verified with the Active Common mode EMI filter; it is possible to use low-voltage transistors for the amplifier by introducing coupling capacitors between the power line and the amplifier circuit. Thus the ACEF can be applied to various power electronic systems regardless of the working voltage. Also it helps in improving the performance of additional filter stages. The simulation output wave form compared with hardware output wave forms. The hardware for this project is designed and developed for $50 \mathrm{~V}, 50 \mathrm{~Hz}$ three phase FHP motor.

\section{REFERENCES}

Chen, S., 1999. Generation and suppression of conducted EMI from inverter-fed motor drives. Proceedings of the 34th IAS Annual Meeting. Conference Record of the 1999 IEEE Industry Applications Conference, Oct. 3-7, IEEE Xplore Press, Phoenix, AZ, USA., pp: 1583-1589. DOI: 10.1109/IAS.1999.805952

Jin, M. and M. Weiming, 2006. Power converter EMI analysis including IGBT nonlinear switching transient model. IEEE Trans. Ind. Elect., 53: 15771583. DOI: 10.1109/TIE.2006.882009

Karthikeyan, C. and D.K. Duraiswamy, 2011. Simulation of Active Common mode EMI filter for quasi square mode PWM inverter applications. Eur. J. Sci. Res., 54: 600-609. http://www.eurojournals.com/EJSR_54_4_13.pdf

Lubis, Z., A.N. Abdalla, Mortaza and R. Ghon, 2009. Mathematical modeling of the three phase induction motor couple to dc motor in hybrid electric vehicle. Am. J. Eng. Applied Sci., 2: 708712. DOI: $10.3844 /$ ajeassp.2009.708.712

Mohan, N., T.M. Undeland and W.P. Robbins, 2003. Power Electronics: Converters, Applications, and Design. 3rd Edn., John Wiley and Sons, Hoboken, NJ., ISBN: 0471226939, pp: 802.
Nave, M.J., 1989. A novel differential mode rejection network for conducted emissions diagnostics. Proceedings of the IEEE National Symposium on Electromagnetic Compatibility, May 23-25, IEEE Xplore Press, Denver, CO, USA., pp: 223-227. DOI: 10.1109/NSEMC.1989.37184

Nave, M.J., 1991. Power Line Filter Design for Switched-Mode Power Supplies. 1st Edn., Van Nostrand Reinhold, New York, ISBN: 0442004532, pp: 210.

Ogasawara, S. and H. Akagi, 2000. Circuit configurations and performance of the active common-noise canceler for reduction of commonmode voltage generated by voltage-source PWM inverters. Proceedings of the Conference Record of the 2000 IEEE Industry Applications, Oct. 08-12, IEEE Xplore Press, Rome, Italy, pp: 1482-1488. DOI: 10.1109/IAS.2000.882079

Poon, N.K., J.C.P. Liu, C.K. Tse and M.H. Pong, 2000. Techniques for input ripple current cancellation: Classification and implementation. IEEE Trans. Power Elect., 15: 1144-1152. DOI: $10.1109 / 63.892829$

Rao, N.S., G.R. Babu and P.V.S. Srinivas, 2011 Study of electromagnetic radiation and specific absorption rate of mobile phones with fractional human head models via green's functions. J. Comput. Sci., 7: 1275-1283. DOI: 10.3844/jcssp.2011.1275.1283

Skibinski, G.L., R.J. Kerkman and D. Schlegel, 1999. EMI emissions of modern PWM ac drives. IEEE Indus. Applicat. Mag., 5: 47-80. DOI: 10.1109/2943.798337

Son, Y.C. and S.-K. Sul, 2001. Conducted EMI in PWM inverter for household electric appliance. Proceedings of the 36th IAS Annual Meeting. Conference Record of the 2001 IEEE Industry Applications Conference, Sep. 30-Oct. 4, IEEE Xplore Press, Chicago, IL, USA., pp: 2441-2447. DOI: 10.1109/IAS.2001.955963

Takahashi, I., A. Ogata, H. Kanazawa and A. Hiruma, 1997. Active EMI filter for switching noise of high frequency inverters. Proceedings of the IEEE Power Conversion Conference Nagaoka, Aug. 3-6, IEEE Xplore Press, Nagaoka, Japan, pp: 331-334. DOI: 10.1109/PCCON.1997.645634

Tihanyi, L., 1995. Electromagnetic Compatibility in Power Electronics. 1st Edn., IEEE Press, New York, ISBN: 0780304160, pp: 403.

Williams, T., 2007. EMC for Product Designers. 4th Edn., Newnes, New York, ISBN: 0750681705, pp: 498. 